\title{
Política de fundos na educação e desigualdades municipais no estado de São Paulo: uma análise a partir das arenas políticas de Lowi
}

\author{
Rogério Machado Limonti \\ DIEESE \\ Ursula Dias Peres \\ EACH/USP \\ Eduardo de Lima Caldas \\ EACH/USP
}

\begin{abstract}
A sistematização das políticas sociais no Brasil vem sendo tratada de forma incremental nas últimas décadas, sendo a Constituição de 1988 um marco histórico ao reafirmar a importância de estados e municípios na oferta dessas políticas, em especial, na educação. Durante a década de 1990, percebe-se, no entanto, dificuldades na relação dos entes federativos para a condução de políticas educacionais. São então implementadas diversas modificações, como a aprovação do Fundef, que foi alterado em 2006, com a aprovação do Fundeb. Essas mudanças implicaram distorções e iniquidades na distribuição de recursos da educação nos municípios do estado de São Paulo. Este artigo busca discutir essas distorções, a partir da adoção dos dois fundos constitucionais, à luz das arenas de políticas públicas de Lowi $(1966,1972)$.
\end{abstract}

Palavras-chave: educação; Fundeb; orçamento; gestão pública e governança.

Política de fondos de la educación y desigualdades municipales en el estado de São Paulo: un análisis desde el ámbito político de Lowi

La sistematización de las políticas sociales en Brasil se están abordando gradualmente en las últimas décadas, la Constitución de 1988 es un hito histórico en la reafirmación de la importancia de los estados y municipios para ofrecer a sus políticas, especialmente en la educación. Durante la década de 1990, está claro, sin embargo, las dificultades en la relación de las entidades federativas para llevar a cabo las políticas. Se implementan cambios en la aprobación de un fondo para la educación, el Fundef, que fue modificado en 2006, con el Fundeb. Estos cambios profundos conllevaran distorsiones y desigualdades en los municipios del estado de São Paulo. Este artículo analiza estas distorsiones, con cargo a la aprobación de los fondos, a la luz de las arenas políticas públicas de Lowi $(1966,1972)$.

Palabras clave: educación; Fundeb; presupuesto; gestión pública y governança.

http://dx.doi.org/10.1590/0034-76121430

Artigo recebido em 9 jan. 2013 e aceito em 18 dez. 2013.

Rev. Adm. Pública - Rio de Janeiro 48(2):389-409, mar./abr. 2014 
Funding policy in education and municipal inequalities in the State of São Paulo: an analysis from the political arenas of Lowi

The systematization of social policies in Brazil is being addressed incrementally in recent decades. The 1988 Constitution is a historic milestone in reaffirming the importance of states and municipalities to offer these policies, especially in education. During the 1990s, however, some difficulties are seen in the relationship of federal entities to conduct educational policies. Then they implemented several changes to the approval of a fund for education, Fundef, which was amended in 2006, with the approval of Fundeb. These changes caused distortions and inequities in the distribution of education resources in the municipalities in the State of São Paulo. This article discusses these distortions from the approval of these two funds, in the light of public policy arenas by Lowi $(1966,1972)$.

KEYWORDs: education; Fundeb; budget; public management and governance.

\section{Introdução}

A implementação das políticas sociais no Brasil vem sendo tratada de forma incremental nas últimas décadas, sendo a Constituição Federal de 1988 um marco histórico que traz certa clareza ao processo ao reafirmar a importância de estados e municípios na oferta dessas políticas, em especial na educação.

O cenário no final da década de 1980 e início da década de 1990 mostrou-se pouco promissor em termos de avanços na oferta desses serviços, em especial no que diz respeito à universalização do ensino fundamental, uma das prioridades constitucionais (Rodriguez, 2001).

Além de ser uma prioridade constitucional, a universalização do ensino fundamental constitui-se na década de 1990 em uma meta de governo, cuja estratégia de busca implicou a reorganização financeira do sistema de educação básica, a revisão da Lei de Diretrizes e Bases da Educação Nacional (LDB) e inclusive a aprovação de um fundo de recursos para a educação, o Fundo de Manutenção e Valorização do Ensino Fundamental (Fundef), por meio de uma emenda constitucional.

Essas mudanças ocorridas na educação na década de 1990, somadas a mudanças mais recentes, novamente de reorganização financeira da educação básica, ocorridas em 2006 com a aprovação do Fundo de Manutenção e Desenvolvimento da Educação Básica e de Valorização dos Profissionais da Educação (Fundeb), implicaram alterações profundas nas administrações municipais brasileiras, no que diz respeito à oferta de ensino público e também à sua estrutura orçamentária-financeira.

Este artigo busca discutir as mudanças ocorridas nas administrações públicas municipais a partir das subvinculações orçamentárias introduzidas com o Fundef e, mais recentemente, o Fundeb.

Para isso, na próxima seção serão apresentados com mais detalhe os objetivos e a metodologia do trabalho. O histórico das regras constitucionais da educação e as alterações financeiras das últimas décadas são tratados na seção três com vistas a elucidar o leitor sobre o contexto institucional no qual se insere este trabalho. 
Já na seção quatro apresentamos nossa escolha de marco teórico para análise das políticas de educação. As arenas de políticas públicas utilizadas por Lowi $(1966,1972)$ nos parecem adequadas a este estudo por permitirem a avaliação das políticas e atores, tanto na formulação, quanto na implementação das políticas de educação. A análise da política em fases é fundamental, visto que a escolha legislativa, que implica a formulação da política, não necessariamente condiciona sua implementação da forma imaginada pelos legisladores, podendo, outrossim, levar a resultados muito diversos e não antecipados.

A seção cinco foi desenvolvida justamente para demonstrar as consequências da escolha da política de subvinculação orçamentária no Fundef e Fundeb para os municípios paulistas, cujo impacto redistributivo de pequenos para grandes municípios chama a atenção por ser o inverso do esperado. As considerações finais são apresentadas na seção seis, juntamente com a análise a partir de Lowi.

\section{Objetivos e metodologia}

O objetivo do trabalho é discutir e qualificar o debate sobre a implementação e o funcionamento do Fundef e Fundeb, no estado de São Paulo.

Este trabalho procura contribuir com respostas a indagações relativas a uma série de mecanismos que mantêm e intensificam a desigualdade entre indivíduos e entre municípios no Brasil.

As questões centrais que orientaram essa pesquisa foram as seguintes: os mecanismos de distribuição de recursos do Fundef e Fundeb reduzem as desigualdades entre os municípios no estado de São Paulo? Por meio desses mecanismos, os municípios pequenos (com menos de 20 mil habitantes) são recebedores líquidos ou doadores líquidos de recursos para o Fundef e Fundeb estadual?

Para responder a essas questões, foi feita uma análise detalhada da legislação que trata do assunto, realizada ampla revisão da literatura que trata do Fundef e do Fundeb, e, finalmente, realizada análise quantitativa (centrada nos aspectos financeiros) acerca dos recursos que constituem o Fundef e o Fundeb, com ênfase e aprofundamento nos 645 municípios do estado de São Paulo, o que conferiu um caráter analítico dedutivo a este trabalho.

Para realização da análise quantitativa foi utilizada fundamentalmente uma amostra significante dos Relatórios de Gestão Fiscal do terceiro quadrimestre de 2009 e os Relatórios Resumidos de Execução Orçamentária de todos os 645 municípios paulistas do mesmo ano, publicados em seus respectivos Diários Oficiais e apresentados à Secretaria do Tesouro Nacional.

De forma complementar, foram analisadoa os resultados do Censo 2010 realizado pelo Instituto Brasileiro de Geografia e Estatística (IBGE) e os microdados do Censo Escolar 2010 realizado pelo Instituto Nacional de Estudos e Pesquisas Educacionais Anísio Teixeira (Inep).

Com a compilação dos dados obtidos a partir das bases e pesquisas citadas foi possível analisar a composição e a distribuição do Fundeb no estado de São Paulo em 2009, considerando as diferenças contributivas entre o estado e os municípios. 


\section{Histórico institucional da educação - período recente}

\subsection{A vinculação tributária constitucional para a educação}

A Constituição Federal de 1988 determina a regra institucional-legal da educação no Brasil e assegura a vinculação de recursos obrigatórios para o ensino nos três níveis de governo. Pinto (2000) relata que a vinculação de recursos à educação não apresenta estabilidade institucional em sua história. A Constituição de 1934 garantia a referida vinculação que, abolida no Estado Novo, foi reincorporada à Constituição de 1946 (art. 169, que garantia 20\% de comprometimento dos municípios para a manutenção e o desenvolvimento do ensino). No período militar, foi novamente retirada. Em 1983, o Congresso promulgou a Emenda Constitucional no 24/1983, conhecida como Emenda Calmon, que determinava a inserção de um novo parágrafo ao art. 176 da Constituição Federal:

Art. 176 - Anualmente a União aplicará nunca menos de treze por cento, e os Estados, o Distrito Federal e os municípios vinte e cinco por cento, no mínimo, da receita resultante de impostos, na manutenção e desenvolvimento do ensino.

O cumprimento da EC no 24/1983, contudo, não foi automático, pois a interpretação do que era a Manutenção e Desenvolvimento do Ensino (MDE) deu margem a muita polêmica. Essa vinculação foi aumentada na Constituição Federal de 1988:

Art. 212 - A União aplicará, anualmente, nunca menos de dezoito por cento, e os Estados, o Distrito Federal e os municípios vinte e cinco por cento, no mínimo, da receita resultante de impostos, compreendida a proveniente de transferências, na manutenção e desenvolvimento do ensino.

A alteração foi uma evidente declaração de prioridade dada à educação, uma vez que se cogitava à época a eliminação das vinculações de receita e apenas a educação teve a vinculação mantida, além de contar com a elevação do percentual mínimo por parte da União (Castro, 2001).

No entanto, o marco legal que definiria a especificidade da MDE continuou pendente.

$\mathrm{O}$ intuito principal da mudança constitucional era, entretanto, o de influenciar o processo de descentralização das ações na área de educação. Essas mudanças, associadas ao aumento da carga tributária destinada aos municípios, visavam aumentar a disponibilidade de recursos orçamentários nas instâncias locais de gasto (Rodriguez, 2001).

Segundo Afonso (2007) e Schmitt (2009), há um importante crescimento da carga tributária, principalmente da receita disponível dos governos locais a partir da Constituição de 1988. Apesar disso, segundo Rodriguez (2001), o aumento da oferta de serviços educacionais nos municípios foi aquém do esperado e muito focalizado no ensino pré-escolar.

Nesse processo, conforme indicado por Azevedo (2000) e Miller (1992), havia evidentemente um problema de assimetria de informação, que dificultava e, muitas vezes, im- 
possibilitava o controle do comportamento dos agentes. Para alguns municípios, principalmente os do Sudeste do país, interessava continuar ofertando somente o ensino pré-escolar, pois para isso contavam com o apoio das redes estaduais de ensino; os outros municípios, com destaque para os da região nordeste, já haviam iniciado um processo de oferta massiva do ensino fundamental. As disparidades e desigualdades regionais e os problemas de assimetria de informação e agência deixavam evidente o cenário crítico do ensino fundamental no país (Peres, 2007).

O processo de descentralização da gestão e financiamento da educação padeceu com a coordenação omissa do governo federal, especialmente com relação ao repasse gradual de poder, de competências e de responsabilidades entre as diferentes esferas administrativas. A ineficiência e a sobreposição de tarefas e atribuições entre níveis de governo tornou-se recorrente, além da criação de ambiente para o comportamento oportunista relativo à utilização dos recursos da educação em diversos locais do país, nas três esferas de governo (Castro, Barreto e Corbucci, 2000).

Na segunda metade da década de 1990, a União muda sua postura e altera as regras para o financiamento do ensino público. A posição oficial passou a ser a de priorizar o ensino fundamental, buscando sua universalização, a partir de uma descentralização efetiva das ações nessa área, sob sua coordenação.

Dessa forma, passou-se a discutir a LDB e a Emenda Constitucional no 14/1996, que deu origem ao Fundo de Manutenção e Desenvolvimento do Ensino Fundamental e Valorização do Magistério (Fundef).

\subsection{A reforma da década de 1990 e o Fundo de Manutenção e Desenvolvimento do Ensino Fundamental e Valorização do Magistério (Fundef)}

A nova LDB reiterou os percentuais de aplicação mínima no ensino fundamental e estabeleceu uma série de regras para os níveis e modalidades de ensino no Brasil. A nova LDB destaca os critérios administrativos e define com maior precisão os gastos em manutenção e desenvolvimento do ensino. A aprovação da emenda constitucional no 14/, no mesmo mês em que foi assinada a LDB, estabelece objetivos semelhantes para a educação nacional. Os artigos alterados da Constituição Federal foram 34, 208, 211 e 212, e o art. 60 do Ato das Disposições Constitucionais Transitórias. As atribuições da União, dos municípios e dos estados são delimitadas especificamente no art. 211.

Nesse artigo, as definições quanto às responsabilidades da União relacionadas ao ensino fundamental são restritas às funções redistributiva e supletiva. Aos estados e municípios criou-se a obrigatoriedade desses entes alocarem $60 \%$ dos recursos vinculados à educação no ensino fundamental, cabendo à União assumir apenas uma função complementar.

A Emenda o 14/1996, regulamentada pela Lei o 9.424/1996 e pelo Decreto no 2.264/1997, define o modo de composição do fundo, a forma de distribuição dos recursos, a definição do custo mínimo nacional, o controle dos repasses e a complementação da União. 
O Fundef era formado por 15\% da contribuição de estados, DF e municípios, dos seguintes impostos e transferências constitucionais: Fundo de Participação dos Estados (FPE); Fundo de Participação dos Municípios (FPM); Imposto sobre Circulação de Mercadorias e Serviços (ICMS); Imposto sobre Produtos Industrializados, proporcional às exportações (IPIexp); e Desoneração de Exportações — Lei Complementar no 87/1996.

Os fundos estaduais contavam com complementação da União quando o valor mínimo nacional por aluno não era alcançado em determinada unidade da federação. Porém, o modelo de cálculo do valor mínimo nacional somente funcionou no primeiro ano de vigência do fundo, posteriormente passou a ser definido por decreto, que fixava valores sempre abaixo da regra anteriormente estabelecida (Davies, 1999).

A distribuição dos recursos para os entes federativos era realizada automaticamente, e levava em consideração o número de matrículas no ensino fundamental das redes de ensino públicas de cada ente federado, do ano anterior ao exercício.

O controle das contas do fundo, as retenções de impostos e transferências dos governos municipais e estaduais, e o crédito dos recursos do Fundo eram efetuados por meio do Banco do Brasil, como esforço para garantir a transparência das referidas movimentações (Calegari, 2010).

A retenção de recursos em fundos estaduais acompanhada pelo repasse (devolutivo) a fundos municipais, condicionado ao número de alunos matriculados nas redes municipais, provocaria o impulso da municipalização do ensino fundamental (Davies, 1999).

O Fundef determinava que no mínimo 60\% dos recursos deveriam ser direcionados ao pagamento de profissionais da área de educação em efetivo exercício, tanto o professor como os profissionais de suporte pedagógico, como forma de valorização do magistério. Os recursos restantes deveriam ser aplicados em manutenção e desenvolvimento do ensino fundamental.

No caso do estado de São Paulo o Fundef proporcionou somente a redistribuição de matrículas no ensino fundamental. A vinculação de parte considerável de recursos ao número de matrículas no ensino fundamental de cada esfera administrativa ocasionou um movimento acelerado de municipalização das matrículas nas séries iniciais do ensino fundamental, os municípios assumiram parte importante da rede estadual para garantir recursos do fundo. Neste momento não ocorreu ampliação do número de vagas no ensino fundamental.

Concomitantemente, as matrículas na educação infantil, as quais não eram consideradas para efeito do Fundef, tiveram baixo crescimento durante toda a vigência do fundo, persistindo o elevado déficit de vagas em creches e pré-escolas.

\subsection{O Fundo de Manutenção e Desenvolvimento da Educação Básica e de Valorização dos Profissionais da Educação - Fundeb}

Em dezembro de 2006, a Emenda Constitucional no 53, que institui o Fundo de Manutenção e Desenvolvimento da Educação Básica e Valorização dos Profissionais da Educação (Fundeb), 
foi aprovada no Congresso Nacional. O modo de funcionamento do novo fundo não foi alterado significativamente. No entanto, algumas diferenças são destacadas, como: o aumento do volume de recursos, seja por meio da complementação da União, seja pela extensão de impostos e transferências a estados e municípios, e também pela diversidade de matrículas contempladas nos vários níveis, etapas e modalidades de ensino.

Em 2007, o governo federal operou o fundo por meio da Medida Provisória no 339, aprovada em 28 de dezembro de 2006. A aprovação da Lei Regulamentar no 11.494 ocorreu apenas em 20 de junho de 2007. Para regular os pormenores do dispositivo, ainda viria uma série de decretos e normas.

A composição dos recursos do Fundeb seguiu a estrutura do fundo anterior, e redirecionou ao fundo parte dos impostos e transferências já vinculados pela Constituição Federal para a manutenção e desenvolvimento do ensino. Os novos impostos vinculados ao fundo Imposto Territorial Rural (ITR), Imposto sobre a Propriedade de Veículos Automotores (IPVA) e Imposto de Transmissão Causa Mortis e Doação (ITCMD) - entraram na base de cálculo gradativamente nos três primeiros anos, e os impostos e transferências que faziam parte do Fundef ampliaram sua participação de $15 \%$ para $20 \%$.

A complementação da União exerce função supletiva e redistributiva, como no caso do Fundef. No entanto, a nova regra difere expressivamente da anterior, no Fundef a União complementava os fundos estaduais que não atingissem o mínimo nacional, que era definido por decreto sem qualquer base de cálculo. ${ }^{1}$

O novo método de cálculo da complementação do Fundeb definiu quantias fixas para os três primeiros anos de vigência, as quais sofreram reajustes para recompor a corrosão da inflação, e a partir do quarto ano a União contribuiria com 10\% de toda a arrecadação dos Fundebs, ou seja, a soma dos 26 fundos estaduais mais o do Distrito Federal.

Este mecanismo, juntamente com um aporte de recursos comparativamente maior do que o do Fundef, possibilitou a ampliação do número de estados que receberiam a complementação, passando de dois em 2006, com o Fundef, para nove estados em 2010, a partir do Fundeb.

A distribuição de recursos dos Fundebs estaduais passou a considerar o número de matriculas de alunos da educação básica pública; assim, incluíram-se as etapas da educação infantil e do ensino médio, e, ainda, incorporaram-se as modalidades de educação de jovens e adultos, educação especial, educação indígena e educação profissional para repartição dos recursos.

A inclusão de toda a educação básica criou uma série de ponderações para distribuição dos recursos, ou seja, o valor aluno anual é diferenciado por etapas, modalidade, tipos de estabelecimento e inclusive por ensino parcial e integral. Para cada ano de vigência do Fundeb novas ponderações balizaram o repasse de recursos. Estas ganharam importância com o novo fundo, pois são capazes de redirecionar grande montante de recursos ao alterarem o peso re-

\footnotetext{
${ }^{1}$ Devido à defasagem dos reajustes, no último ano de vigência do Fundef apenas dois fundos estaduais receberam a complementação (Maranhão e Piauí).
} 
lativo das matrículas; assim, as ponderações representam um instrumento de disputa que vai além da oferta de matrículas de cada ente federativo.

\section{Arcabouço teórico: a pertinência analítica de Lowi para estudar políticas públicas brasileiras}

A abordagem das políticas públicas por meio da elaboração de tipologias se inscreve na tradição weberiana de considerar "tipos ideais". Nesta perspectiva, Lowi $(1966,1972)$ escreveu seus textos sobre políticas públicas nos Estados Unidos, em contexto institucional muito diverso do contexto brasileiro.

A análise proposta por Lowi é relevante na medida em que apresenta uma tipologia de políticas públicas e permite observar os atores, os estilos, bem como as arenas em que transcorrem os processos de negociação tanto para a formulação quanto para a implementação de políticas públicas.

Apesar das diferenças institucionais em que os estudos de Lowi $(1966,1972)$ foram desenvolvidos, as categorias analíticas por ele utilizadas bem como sua classificação de políticas públicas são pertinentes e influenciaram trabalhos de alguns poucos estudiosos brasileiros, dentre os quais: Carvalho e Costa (1988), Carvalho (1995), Santos (1997), Ricci (2002) e Laczynski (2012).

Lowi (1966) utilizou dois critérios para classificar as políticas públicas em distributivas, regulatórias e redistributivas. Os dois critérios foram os seguintes: o impacto da política na sociedade (restrito e benéfico a um pequeno grupo de pessoas ou ampliado e gerando benefícios a um grupo e prejuízos a outro grupo); e o espaço onde se desenrolam as negociações em torno dos conflitos gerados pelas políticas públicas.

As políticas classificadas como distributivas são aquelas que geram benefícios concentrados para um grupo restrito de atores e custos difusos que recaem sobre o conjunto da sociedade. Esse tipo de política não está constrangido ou limitado por restrições orçamentárias. Esse tipo de política ocorre em arenas pouco conflituosas.

O baixo nível de conflito é explicado pelo dilema de ação coletiva. Como as políticas distributivas beneficiam pequenos grupos (geram baixo custo de organização para o referido grupo em face dos benefícios gerados para eles próprios), então facilitam a organização dos referidos grupos em torno de seus interesses; e pulverizam o custo para o conjunto da sociedade (gerando alto custo de organização da sociedade). Dessa forma, as políticas distributivas não criam muitos conflitos entre interesses diferenciados. Assim, as políticas distributivas ocorrem em arenas pouco conflituosas.

Exemplos de políticas distributivas são aquelas relacionadas com políticas públicas de subsídios, e gratuidades de taxas para certos grupos sociais.

Para Lowi (1966), as políticas distributivas são adequadas para o atendimento de demandas individuais e mais compreendidas como cooptação do que como conflito e compromisso. 
Assim como as políticas distributivas, as políticas regulatórias também têm impactos específicos e individualizados, mas não são facilmente desagregadas. Embora as políticas regulatórias (leis e regulamentos) recaiam sobre o conjunto da sociedade, ou seja, sejam feitas em termos gerais, e não específicas a partir da pressão de grupos organizados, seus efeitos alteram as estruturas de custos dos agentes individuais. As regras (leis ou regulamentos) que definem rotas de voo para o exterior são gerais, mas definem a empresa vencedora "permissionária" do uso da referida linha (bem como as perdedoras) e alteram estruturas de custos das empresas que concorrem pelo benefício da referida linha. Esse tipo de política favorece o conflito, pois, no curto prazo, envolve uma escolha direta entre quem será favorecido e quem será desfavorecido.

As políticas redistributivas, por sua vez, assemelham-se às políticas regulatórias na medida em que são generalizáveis e envolvem setores sociais mais abrangentes (e não são facilmente atomizadas). Neste tipo de política deve ficar muito evidente qual é o setor que arcará com o custo e qual é o setor beneficiário. Uma política de renda mínima para um grupo social vulnerável é distributiva. Uma política de renda mínima para o mesmo grupo vinculada à criação ou ao aumento de um imposto que incida diretamente sobre outro setor é redistributiva.

Neste tipo de política os impactos recaem sobre categorias tais como classes sociais, ricos e pobres, grandes e pequenos, burgueses e proletários. Neste caso, não existem mais de dois lados nitidamente identificáveis, estáveis e consistentes.

Para Lowi (1966), os processos decisórios sobre políticas distributivas e regulatórias ocorrem fundamentalmente no Congresso (composto por atores com grande capacidade de barganha), enquanto as políticas redistributivas, altamente conflituosas, exigem processos mais complexos em escala mais ampla, são elaboradas e implementadas pelo Poder Executivo.

Assim, quando os interesses nas questões tornam-se interesses compartilhados, com ampla identidade, generalizáveis e antagonizados entre dois grandes grupos, os termos definidos são os redistributivos. Por outro lado, quando os interesses são mais focados, seja em termos setoriais, geográficos ou individuais, o fator comum que une os interesses torna-se passível de negociação.

Lowi (1972) acrescenta uma quarta política pública: a constituinte. As políticas constituintes são aquelas que visam a criação ou modificação da estrutura de governo ou das relações de poder e o estabelecimento de regras pela adoção de decisões públicas. Se no estudo inicial Lowi (1966) estava preocupado em compreender os tipos de arena em que as políticas são elaboradas e implementadas e em classificar as políticas de acordo com seu impacto, no estudo posterior, Lowi (1972) está preocupado com os tipos de coerção que estas políticas geram.

Para Lowi (1972), tanto as políticas distributivas quanto as constituintes têm probabilidade de coerção remota; enquanto as políticas regulatórias e redistributivas têm probabilidade coercitiva imediata.

Se a probabilidade coercitiva aproxima as políticas distributivas das constituintes, e as políticas regulatórias das redistributivas, deve-se considerar que o impacto coercitivo aproxima as políticas distributivas das regulatórias, e as políticas constitutivas das redistributivas. 
Para Lowi (1972), tanto as políticas distributivas quanto as regulatórias têm impacto coercitivo individual; enquanto as políticas constituintes e redistributivas incidem coercitivamente sobre o coletivo.

Apesar das diferenças de objetivos e dos contextos institucionais entre Lowi $(1966,1972)$ e os autores brasileiros (Carvalho e Costa, 1988; Carvalho, 1995; Santos, 1997; Ricci, 2002; Laczynski, 2012), observa-se a pertinência em adotar suas categorias analíticas, desde que:

1. As categorias criadas por Lowi $(1966,1972)$ para interpretar e classificar as políticas públicas sejam reconhecidas como tipos ideais e a partir do referido reconhecimento sejam feitas análises nas quais as políticas públicas possam ser observadas como híbridas, ou seja, encaixadas em mais de uma categoria;

2. Fique evidente que a unidade de análise de Lowi $(1966,1972)$ é o indivíduo e que análises como a proposta neste artigo utilizam como unidade de análise o município. Isso implica profundas adaptações, mas não invalida a pertinência das categorias propostas.

\section{Apresentação dos dados da pesquisa: a redistribuição dos recursos por meio dos fundos de financiamento da educação: um recorte sobre os municípios paulistas}

Para identificar se o fundo realmente proporciona prejuízos financeiros para um determinado grupo de municípios, serão abordados três pontos: $i$. A receita tributária dos municípios paulistas, com ênfase na dinâmica do ICMS e do FPM; ii. A tendência do resultado financeiro do Fundeb nos municípios; iii. E, por fim, o comportamento das matrículas da educação básica.

\subsection{Receita tributária dos municípios paulistas}

Nos três primeiros anos do Fundeb houve uma contribuição expressiva do ICMS na composição dos recursos do fundo, com participação acima de 80\%. Já o IPVA e o FPM/FPE têm certa estabilidade na participação e contribuem com taxas que variam entre 7\% e 9\% (Calegari, 2010).

Após verificar quanto cada imposto contribui ao Fundeb paulista, cabe analisar os efeitos que este provoca sobre a natureza dos impostos, pois o fundo institui uma estrutura rígida, na qual impõe que $20 \%$ de determinados tributos comporão o fundo de cada estado, o que altera a dinâmica da distribuição de receitas tributárias municipais. Conforme observado por Pinto (2007), a política de financiamento da educação por meio de fundos modifica significativamente a natureza de duas receitas municipais, o ICMS e o FPM, proporcionando tendências distintas.

A cota-parte dos municípios referente ao ICMS equivale a 25\% do arrecadado pelo estado, e 75\% da cota municipal destinam-se aos municípios onde o imposto foi recolhido. Desta forma, "os municípios mais industrializados são aqueles que apresentam as maiores 
receitas per capita do país, já que a maior parte da arrecadação do ICMS advém da atividade industrial" (Pinto, 2007).

Os fundos de financiamento da educação alteram a forma de distribuição dos recursos, uma vez que, ao reterem a parcela do ICMS destinada ao fundo, os recursos serão posteriormente distribuídos segundo o número de matrículas no ensino fundamental, no caso do Fundef, ou da educação básica, no caso do Fundeb.

Pinto (2007) avalia que esta mudança imposta pelo Fundeb para repartição do ICMS é positiva, pois significa que os municípios com maior receita tendem a transferir recursos para aqueles com menor arrecadação, o que o autor nomeia como efeito "Robin Hood".

Tal redistribuição seria desejável, devido à natureza indireta do tributo - a qual consiste no consumidor final pagar pelo tributo. Por isso, seria justa a distribuição dos recursos a todos os municípios, pois esse tributo seria pago indiretamente por toda população.

Por sua vez, o FPM teria um efeito inverso, os municípios menores contribuiriam proporcionalmente com mais recursos ao Fundeb do que os municípios de grande porte. Isto devido à característica de distribuição dos recursos do FPM, a qual adota uma relação inversamente proporcional ao tamanho da população municipal, ou seja, a União transfere um valor maior por habitante para os municípios com população menor.

Desta forma, o mecanismo do Fundeb enfraquece o efeito do FPM nos municípios menores, uma vez que redistribui a todos os municípios os $20 \%$ oriundos do FPM; isto criaria um efeito de "Robin Hood às avessas", ao retirar recursos dos municípios menores e redistribuir aos maiores (Pinto, 2007).

Ilustrativamente, para entender o impacto do Fundeb, vale destacar os dois extremos das municipalidades do estado de São Paulo. Primeiramente, o município de Borá - o menor município do estado, que em 2009 obteve R\$ 4 milhões do FPM, que representava 60,5\% da sua receita corrente líquida. Em contraposição, o FPM destinado ao município de São Paulo era de $\mathrm{R} \$ 115,8$ milhões, que significava apenas $0,5 \%$ da sua receita corrente líquida. $\mathrm{O}$ mecanismo do Fundeb ao recolher 20\% do FPM retira de Borá 12,1\% da sua receita e somente 0,1\% do município de São Paulo.

Ao estender essa análise para todos os municípios paulistas, verifica-se que a parte do FPM destinada ao Fundeb em 2009 pelos municípios com população de até 5 mil habitantes equivale, em média, a $9,57 \%$ da receita corrente líquida, a qual diminui conforme o porte demográfico do município aumenta, e representa apenas 0,23\% da receita corrente líquida para o grupo de municípios com população superior a 500 mil habitantes, uma diferença de mais de 40 vezes.

Portanto, os dados confirmam que a cota-parte do FPM destinada ao Fundeb representa um montante significativamente maior para as finanças municipais dos entes menores, enquanto tem baixíssima representação nos municípios com mais de 500 mil habitantes.

Os recursos do FPM destinados ao Fundeb seguem uma tendência segundo as faixas populacionais dos municípios; isto revela a importância dessa transferência constitucional para as administrações municipais de pequeno porte. Porém, resta saber o impacto dos demais 
impostos e transferências que compõem o Fundeb, já que os outros impostos podem apresentar graus de representação distintos nas finanças municipais e alterar substancialmente a tendência apresentada pelo FPM.

A participação das receitas dos municípios paulistas destinadas ao Fundeb sobre a receita corrente líquida reafirma a tendência do ponto anterior, uma vez que os municípios com população de até 5 mil habitantes comprometem uma parcela maior (15,53\%) da sua receita corrente líquida. Os municípios com população entre 5 mil e 10 mil e entre 10 mil e 20 mil destinam ao fundo $13,55 \%$ e $12,87 \%$ da sua receita, respectivamente. As administrações municipais entre 20 mil e 100 mil habitantes ficam em média entre 10,30\% e 11,01\%. Na faixa populacional de 100 mil a 500 mil a relação é de 8,57\%, e nos municípios com mais de 500 mil habitantes, o comprometimento é de apenas 6,5\% da receita corrente líquida. A relação com as faixas populacionais é direta, porém diminui a amplitude da diferença entre a primeira e a última faixa populacional, que fica em $135 \%$.

Os dados confirmam que os municípios com pequeno porte contribuem mais proporcionalmente do que os maiores, isto em grande parte devido ao modo de repartição dos recursos do FPM e pela estrutura rígida do Fundeb.

Porém, a destinação proporcionalmente maior de recursos dos municípios menores ao Fundeb não caracteriza, em si, um processo de desigualdade, pois a forma em que os recursos retornam aos municípios não guarda relação direta com a arrecadação, mas com o número de matrículas na Educação Básica. Desse modo, os municípios recebem quantias diferentes do que as destinadas ao Fundo, o que precisa ser analisado.

\subsection{Tendência do resultado financeiro do Fundeb nos municípios}

Tendo em vista os resultados do item anterior, é necessário identificar quais municípios apresentam resultado negativo ou positivo em suas finanças em relação ao Fundeb, o que usualmente se chama de ganho ou perda de recursos.

Ressalte-se que a implantação dos fundos prezava pelo princípio da equidade, isto é, sabia-se previamente que municípios perderiam recursos e por consequência outros ganhariam, pois este dispositivo contribuiria para que os recursos da educação fossem redistribuídos equitativamente, diminuindo assim as desigualdades educacionais entre municípios de um mesmo estado.

$\mathrm{Na}$ análise dos dados financeiros dos municípios paulistas, conforme seu porte demográfico, verifica-se que a maioria $(86,8 \%)$ dos entes com até 5 mil habitantes apresenta perdas de recursos; as taxas para os demais municípios apresentam redução proporcional ao tamanho dos municípios. Na faixa de municípios com população de 5 mil a 10 mil habitantes, 46,7\% destes obtiveram perdas; na faixa entre 10 mil e 100 mil habitantes, as perdas variam em média de $23,8 \%$ a 20,4\% dos municípios. Os municípios entre 100 mil e 500 mil habitantes apresentam perdas em 15,6\% dos casos, e nas administrações municipais com mais de 500 mil, apenas três municípios apresentam perdas, o que representa 33\% dos municípios. 


\subsection{Comportamento das matrículas da Educação Básica}

Ao verificar que a dinâmica das perdas municipais segue uma tendência prejudicial aos pequenos municípios, cabe verificar se esse movimento ocorre devido à falta de matrículas em suas respectivas redes de ensino, ou se isso acontece por causa do formato do fundo.

As matrículas serão verificadas sob duas vertentes: ${ }^{2}$ a primeira medirá a participação do poder municipal na oferta de vagas, e a segunda analisará quanto da população em idade escolar está sendo atendida pelos municípios. Nessas vertentes são analisadas as matrículas de competência municipal - a educação infantil e o ensino fundamental — e ainda as matrículas da educação de jovens e adultos.

A educação infantil é dividida em duas etapas, creches para crianças de 0 a 3 anos, e pré-escola para crianças de 4 a 5 anos de idade. Em 2010, as matrículas em creches municipais representaram $56,4 \%$ de todas as matrículas dessa etapa de ensino, as creches comerciais atendiam $24 \%$ e as creches comunitárias possuíam 19,4\% das matrículas; no entanto, a oferta é desigual entre os municípios.

Nos municípios com até 5 mil habitantes, 91,1\% das matrículas são oferecidas diretamente pelo poder público municipal; já nos municípios com mais de 500 mil habitantes, o percentual é de apenas 37,5\% (tabela 1).

No caso da pré-escola, o atendimento municipal é responsável por praticamente todas as matrículas nas faixas populacionais iniciais, com taxas de $98,9 \%$, e $99 \%$, nas faixas populacionais de até 5 mil habitantes e de 5 mil a 10 mil, respectivamente. As demais faixas seguem a tendência observada nas matrículas em creches, uma vez que, conforme aumenta o porte demográfico do município, diminui sua participação na oferta de vagas, pois o poder privado assume parte da demanda. Nos municípios com mais de 500 mil habitantes o poder público municipal representou apenas $71,6 \%$ das matrículas, o restante $(28,4 \%)$ foi ofertado pelo poder privado (tabela 1 ).

Em 2010, completaram-se 13 anos da política de financiamento por fundos no ensino fundamental. No estado de São Paulo as matrículas foram fortemente municipalizadas durante os anos do Fundef, alterando extremamente a participação do estado e dos municípios. A municipalização continuou na vigência do Fundeb, mas dessa vez em ritmo mais lento.

A relação entre estado e municípios paulistas aponta traços particulares após o expressivo processo de municipalização. No ensino fundamental, os municípios com até 20 mil habitantes são responsáveis por volta de $59 \%$ a $65 \%$ das matrículas dos seus territórios. Os municípios na faixa de 20 mil a 100 mil habitantes têm uma participação menor, com taxas entre 50\% e 57\%. Por fim, os municípios acima de 100 mil habitantes têm uma representação menor do que a do Estado, enquanto os municípios entre 100 mil e 500 mil detêm apenas

\footnotetext{
${ }^{2}$ As matrículas nas duas vertentes são referentes ao Censo Escolar (Inep) de 2010. O exercício de 2010 foi escolhido para se adequar com a base de comparação aos dados do Censo 2010 (IBGE).
} 
$40,7 \%$ das matrículas e o estado atende $44,6 \%$, e na faixa acima de 500 mil habitantes, os municípios oferecem somente $29,7 \%$ das matrículas, enquanto a rede estadual atende 49,5\% das matrículas.

Na modalidade de educação de jovens e adultos, o atendimento nas administrações municipais com até 5 mil habitantes representava 40,9\% da oferta das matrículas nos seus territórios, já os municípios entre $5 \mathrm{mil}$ e $10 \mathrm{mil}$, e de $10 \mathrm{mil}$ a $20 \mathrm{mil}$, atingiram taxas de $36,7 \%$ e $39 \%$, respectivamente. Nos municípios da faixa populacional entre 20 mil a 50 mil habitantes, a relação foi de $35,6 \%$, e nas duas faixas superiores, de 50 mil a 100 mil, e de 100 mil a 500 mil, as taxas foram de 33,2\% e 32,5\%, respectivamente. Por fim, nos municípios com população acima de 500 mil habitantes, a participação ficou em 39,4\%, devido à forte influência do município da capital, que tem uma oferta na ordem de 44,27\%.

Os municípios paulistas ofertam mais matrículas do que o estado no ensino infantil, seja na creche ou na pré-escola, e as matrículas no ensino fundamental nos municípios com até 20 mil habitantes são, em sua maioria, financiadas pelo poder municipal (tabela 1).

Tabela 1

Atendimento pela rede municipal de ensino em relação às demais redes de ensino, por etapa de ensino

Municípios paulistas, 2010

\begin{tabular}{|lcccc|}
\hline Municípios por Faixa Populacional & Creche & Pré-escola & $\begin{array}{c}\text { Ensino } \\
\text { Fundamental }\end{array}$ & $\begin{array}{c}\text { Educação de } \\
\text { Jovens e Adultos }\end{array}$ \\
\hline Até 5 mil habitantes & $91,1 \%$ & $98,9 \%$ & $59,4 \%$ & $40,9 \%$ \\
De 5 mil até 10 mil habitantes & $86,8 \%$ & $99,0 \%$ & $64,7 \%$ & $36,7 \%$ \\
De 10 mil até 20 mil habitantes & $77,3 \%$ & $93,2 \%$ & $62,3 \%$ & $39,0 \%$ \\
De 20 mil até 50 mil habitantes & $79,2 \%$ & $90,0 \%$ & $56,4 \%$ & $35,6 \%$ \\
De 50 mil até 100 mil habitantes & $77,8 \%$ & $86,8 \%$ & $49,7 \%$ & $33,2 \%$ \\
De 100 mil até 500 mil habitantes & $63,6 \%$ & $81,2 \%$ & $40,7 \%$ & $32,5 \%$ \\
Acima de 500 mil habitantes & $37,5 \%$ & $71,6 \%$ & $29,7 \%$ & $39,4 \%$ \\
Total & $56,4 \%$ & $78,9 \%$ & $40,1 \%$ & $36,4 \%$ \\
\hline
\end{tabular}

Fonte: Censo Escolar 2010/Inep. Elaborado pelos autores.

Em todas as etapas de ensino verifica-se que a participação do poder municipal é maior nos municípios com até 5 mil habitantes, quando comparada aos municípios com mais de 20 mil habitantes. Assim, os dados permitem afirmar que as perdas financeiras dos pequenos municípios não decorrem da sua participação na divisão das responsabilidades com o governo do estado.

As administrações municipais com população até 5 mil têm mais matrículas em seus territórios do que a União, o estado e a rede particular; porém resta saber se essa oferta atende a uma parcela pequena da sua população. Por isso, se analisará quanto da população em idade escolar é atendida pelos municípios no ensino infantil e no ensino fundamental. 
Para verificar a oferta de vagas pelos municípios em comparação com a população em idade escolar por etapa de ensino, utilizaram-se os dados dos residentes em cada município, por grupo de idade do Censo 2010 (IBGE). O número de matrículas da Educação Básica foi obtido por meio do Censo Escolar 2010 (Inep), e a legislação do Fundeb foi utilizada para definir a metodologia de filtragem dos dados, por faixa etária adequada, conforme cada etapa de ensino.

Em 2010, as matrículas em creches representavam, em média, 22,8\% da população de 0 a 3 anos e 11 meses do estado de São Paulo, isso quando consideradas somente as matrículas financiadas pelo poder público municipal. Os municípios com até 5 mil habitantes atendiam 33,7\% das crianças dessa faixa etária, enquanto os demais municípios oscilavam entre $28,6 \%$ e $19,9 \%$. As demais esferas públicas têm pequena participação nessa etapa de ensino (tabela 2).

Os dados também demonstram como o atendimento de creches ainda é pequeno, e há grande demanda para expansão dessa etapa de ensino, cerca de 1,5 milhão de crianças ainda não recebe atendimento no estado de São Paulo.

Na educação infantil ainda se considera a etapa de ensino pré-escolar; nesta, todas as faixas municipais encontram-se próximas, mas ressalta-se que as duas faixas menores são as únicas a atenderem mais de $80 \%$ da população em idade adequada. A oferta de vagas é ampliada quando se consideram as demais esferas públicas e as escolas particulares; assim, todas as faixas atendem mais de $80 \%$ da população.

O ensino fundamental no estado de São Paulo é universalizado em todas as faixas municipais, quando considerada a participação do poder público e das redes particulares de ensino, pois o número de matrículas é superior ao número de residentes com idade entre 6 e 14 anos.

As matrículas nos municípios menores atendem uma parcela representativamente superior da sua população quando comparada com os maiores municípios. As administrações locais com até 5 mil habitantes atendem $62,9 \%$ da sua população em idade escolar, os municípios com população entre 5 mil e 10 mil, e de 10 mil a 20 mil, atendem 67,5\%, e 65,4\%, respectivamente. Os entes na faixa de 20 mil a 50 mil têm 59,6\% de participação, e aqueles na faixa de 50 mil a 100 mil atendem 53,2\%. Já nas faixas superiores, a participação fica em 43,9\% nos municípios entre 100 mil e 500 mil habitantes, e em 31,9\% quando considerados os municípios acima de 500 mil (tabela 2).

Portanto, a oferta de vagas no ensino fundamental pelos municípios menores é relativamente maior do que a verificada nos médios e grandes municípios. No caso do ensino infantil, seja na creche ou na pré-escola, se não há uma diferença significativa para afirmar que os pequenos municípios atendem uma parcela maior da sua população do que os demais entes municipais, também não há subsídios para sustentar uma tendência contrária, ou seja, os municípios menores atendem uma parcela igual ou maior da sua população, em comparação aos demais municípios (tabela 2). 
Tabela 2

Atendimento pela rede municipal de ensino da população

em idade escolar, por etapa de ensino

Municípios paulistas, 2010

\begin{tabular}{|lccc|}
\hline Municípios por Faixa Populacional & Creche & Pré-escola & Ensino Fundamental \\
\hline Até 5 mil habitantes & $33,7 \%$ & $83,6 \%$ & $62,9 \%$ \\
De 5 mil até 10 mil habitantes & $24,7 \%$ & $81,8 \%$ & $67,4 \%$ \\
De 10 mil até 20 mil habitantes & $22,2 \%$ & $76,8 \%$ & $65,4 \%$ \\
De 20 mil até 50 mil habitantes & $23,8 \%$ & $78,6 \%$ & $59,6 \%$ \\
De 50 mil até 100 mil habitantes & $28,6 \%$ & $78,7 \%$ & $53,2 \%$ \\
De 100 mil até 500 mil habitantes & $24,3 \%$ & $67,9 \%$ & $43,9 \%$ \\
Acima de 500 mil habitantes & $19,9 \%$ & $77,9 \%$ & $31,9 \%$ \\
Total & $22,8 \%$ & $74,9 \%$ & $43,0 \%$ \\
\hline
\end{tabular}

Fonte: Censo Escolar 2010/Inep. Elaborado pelos autores.

Desta maneira, as perdas financeiras em pequenos municípios não são justificadas por uma pequena participação destes na divisão da responsabilidade de oferta entre estado e municípios, e também não encontra respaldo o argumento de que os municípios não ampliaram suas redes de ensino. Assim, mesmo após os entes locais com pequena população se responsabilizarem por parte expressiva das matrículas e atenderam parte importante de sua população escolar, ainda permanecem apresentando perdas financeiras com o Fundeb.

Dessa forma, quando o Fundeb retém 20\% do FPM para sua composição, atinge mais intensamente a receita dos municípios menores. No caso dos municípios paulistas, os demais impostos ainda amenizam esse efeito, mas não o eliminam totalmente. Deste modo, verificase que os municípios menores contribuem com uma parte proporcionalmente maior da sua receita ao Fundeb.

Esse fato explica as perdas financeiras em 2009 de 138 municípios paulistas com até 5 mil habitantes, o que equivale a $86,8 \%$ das administrações municipais dessa faixa populacional no estado de São Paulo. As perdas financeiras também poderiam ocorrer devido ao baixo oferecimento de matrículas na educação básica pelos entes locais; no entanto, tal tese não se sustenta, uma vez que os municípios menores detêm um número de matrículas proporcionalmente superior às demais esferas, nas redes pública ou privada, nos seus territórios, e ainda atendem parcela maior da população em idade escolar quando comparados com as demais municipalidades.

Perante isto, pode-se afirmar que a implementação do Fundeb no estado de São Paulo, sob os atuais critérios, não possibilita a equidade de condições entre os entes federativos locais como se pretendia com a criação dos fundos, pois estruturalmente apresenta distorções em seu funcionamento, que prejudicam os entes mais frágeis economicamente no estado de São Paulo. 


\section{Considerações finais e aprendizados a partir da análise de políticas públicas}

É interessante analisar o processo reformista da educação no período recente, mais propriamente a instituição dos fundos, Fundef e Fundeb, na perspectiva das arenas de Lowi.

A primeira questão importante a se pensar é que neste texto assumimos como unidade analítica os municípios, diferentemente de Lowi, que trata de indivíduos. Isto se dá pois a pesquisa foi calcada em dados dos municípios paulistas e não nos é possível individualizar o resultado dessas políticas públicas.

Segundo Lowi, quatro são as arenas possíveis de análise das políticas públicas: a arena distributiva, a regulatória, a redistributiva e a constitutiva. Esta análise em arenas é feita a partir de tipos ideais, que são dificilmente encontrados na realidade das políticas públicas. No entanto, esta tipificação ajuda a pensar que inter-relações podem existir entre as arenas e o que estas podem explicar sobre as características de cada política. A combinação e até mesmo a contraposição das arenas ajudam a entender a política pública e suas consequências. Dessa maneira, entendemos que não se enquadra perfeitamente a política pública em uma das arenas, mas ao analisar essa política a partir dos parâmetros de cada arena, tornam-se mais perceptíveis seus contornos e resultados.

Nesse sentido, analisando a política dos fundos na perspectiva distributiva, temos dois grandes elementos a considerar: a perspectiva da distribuição de renda entre os indivíduos, ou, no caso desta pesquisa, entre os municípios paulistas, e o nível de conflito existente na formulação e implementação da política. Em relação à distribuição de renda, vemos que a política não tem o foco de uma cobrança específica voltada para a distribuição de renda; antes, sim, possibilita a redistribuição desta entre municípios de um mesmo estado e o ente estadual, em função do critério de matrículas, o que não torna claro seu enquadramento. Além disso, uma arena distributiva tem baixa incidência de conflito; ainda que esse possa parecer o caso do Fundef/Fundeb, na prática não é verdade, pois há conflito latente, em especial na fase de implementação. Esse conflito tornou-se aparente na implementação do Fundef, obrigando ao longo dos anos sua revisão e mudança para o Fundeb o qual está agora também em fase de conflito latente, pois os atores não estão satisfeitos com as condições da política, mas por não terem perfeita consciência das consequências financeiras desta, não há ainda um conflito claro.

Do ponto de vista da arena regulatória, também não parece ser essa a essência da política, visto que se percebe no processo uma clara proatividade do Poder Executivo na determinação e elaboração da política (federal) e na execução desta (estados e municípios). Além disso, como a política não foi pensada em seus detalhes, não contou com análise de impacto ex ante, não há a possibilidade de definição de ganhadores e perdedores, como seria requerido. Isto porque, dada a diversidade política, fiscal e gerencial dos municípios, diferentes cenários antes e depois da política podem ser esperados.

Um dos preceitos básicos da teoria de Lowi $(1966,1972)$ é de que a policy determina a politcs, ou seja, de que o formato e o conteúdo da política determinariam o processo político, pois parte do pressuposto de que as reações e expectativas dos atores envolvidos com tais políticas geram um efeito que antecipa o processo decisório. 
A análise dos mecanismos do Fundef induz a associação preliminar com a arena redistributiva, uma vez que os recursos vinculados à educação serão repartidos dentre os municípios de um estado, e entre os municípios e o governo estadual; assim, se obtém o entendimento de que os entes federativos que atendessem ao maior número de alunos seriam premiados com um montante de recursos superior, e os que não tivessem um regime próprio perderiam recursos, ou seja, ocorreria uma redistribuição de recursos direta entre ganhadores e perdedores.

Essa redistribuição, no entanto, não apresenta a característica apontada por Lowi de desconcentração, na qual os recursos públicos migram dos mais ricos para os mais pobres. Os dados analisados indicam que no estado de São Paulo tem existido um processo inverso, no qual os recursos de municípios mais pobres acabam por ser redistribuídos para municípios de grande porte, em função de esses pequenos não terem uma estrutura tributária de forte arrecadação de ICMS. Ao terem sua receita concentrada na cota-parte do FPM, esses municípios ficam sujeitos a uma situação de fragilidade institucional e perdem parte de sua receita, apesar de terem uma rede de ensino com oferta importante de matrículas.

Para Lowi, uma política pública redistributiva geraria um processo político altamente conflituoso, uma vez que os atores identificariam os benefícios e as desvantagens dessa política pública e buscariam as melhores condições para sua implementação.

Porém, o processo desencadeado para constituir o Fundef, mesmo sendo de alta complexidade, pois necessitava de aprovação de uma emenda constitucional, foi marcado por pouca resistência dos autores.

As entidades e organizações da sociedade civil em defesa da educação e da valorização dos profissionais da educação concentravam seus esforços no debate da lei de diretrizes e bases da educação; desta forma, os atores não institucionais tinham uma atenção reduzida ao trâmite do projeto de lei do Fundef no Congresso Nacional.

Os governadores e prefeitos utilizaram critérios técnicos para analisar os impactos da política somente depois de aprovada a emenda constitucional, ou seja, quando seu poder de negociação já estava comprometido, pois não havia grandes possibilidades de rever a decisão.

Os conflitos se concentraram no Congresso Nacional, porém sua tramitação pode ser considerada quase que consensual, em se tratando de uma emenda constitucional que alterava a forma do financiamento da educação para todos os entes federativos.

Em 1996, ano de tramitação da Emenda Constitucional oํ 14, e também ano de eleições municipais, os deputados e senadores sofriam grande desgaste da sua imagem de legisladores, devido a uma crescente pressão da mídia, que apresentava um Congresso Nacional improdutivo e mais preocupado com os pleitos municipais. Assim, para recuperar o prestígio, foi dada celeridade a projetos de lei de grande repercussão popular e o Fundef se encaixou perfeitamente nesse objetivo, visto que se aprovaria um fundo com repercussão nacional e que prometia proporcionar o acesso à rede de ensino público a todas as crianças brasileiras.

Desta forma, o Fundef foi aprovado sem grandes impedimentos, caracterizado inicialmente mais como uma política insulada no Ministério da Educação do que propriamente fruto das disputas dos atores organizados na sociedade, das instituições políticas de estados e municípios, ou dos representantes políticos no Legislativo. 
Isto posto, a abordagem na perspectiva da arena redistributiva fica enfraquecida, pois a implementação da política não foi altamente conflituosa, como previa tal arena. Isto nos permite considerar a quarta arena.

A arena constitutiva é a que nos parece mais razoável na análise do caso, pois a implementação do Fundef nada mais é do que a alteração substancial das regras de financiamento e gerenciamento dos recursos da educação, ou seja, uma modificação da estrutura de governo e das relações de poder econômico dos entes federativos.

Esta arena é marcada por processos consensuais, com pouco impacto na esfera pública, pois em geral se costuma discutir e decidir sobre as modificações do sistema político apenas dentro do próprio sistema político-administrativo, dificilmente tais políticas são de interesse da opinião pública, que geralmente tem foco maior nos conteúdos da política do que nos aspectos gerenciais e burocráticos.

Outra característica desta arena é que, ao trazer uma proposta reguladora e coercitiva para todos, acaba por prejudicar a perspectiva de uma política equânime. O próprio fato de ser igual para todos os municípios a torna desigual ao não considerar necessidades específicas de cada tipologia de municípios, tão diferentes no estado de São Paulo, como de resto em todo o Brasil. A equidade, conforme ressalta Rawls (2000), implica a consideração de políticas públicas que tratem desigualmente os desiguais. Esse conceito, associado ao da arena distributiva, torna a política de fundos uma política de distribuição perversa, ao permitir a ocorrência de um efeito Robin Wood às avessas, como demonstrado no item 5.

Além disso, Klaus Frey (2000) complementa a abordagem de tal arena, ao propor o conceito de "políticas estruturadas de sistema", as quais não expressam simplesmente a manutenção ou consolidação do sistema atual, mas também a transformação do atual sistema político. As reformas gerenciais preponderantes na década de 1990 nos países latino-americanos seriam um exemplo típico de tais políticas.

A partir disso, a implementação do Fundef estaria em consonância com tal conceito, pois todas as suas regras visam impor condicionalidades a atividades-meio, ligadas ao controle, à transparência e à distribuição de recursos da educação. Isto reforça o caráter insulado do processo de formulação política no Ministério da Educação, no qual se destacam mais os aspectos institucionais e conjunturais do que propriamente a influência dos atores.

\section{Referências}

AFONSO, José Roberto. Descentralização fiscal, políticas sociais e transferência de renda no Brasil. INSTITUTO LATINOAMERICANO Y DEL CARIBE DE PLANIFICACIÓN ECONÓMICA Y SOCIAL (ILPES); CEPAL. Série Gestão Pública, n. 63, Santiago do Chile, fev. 2007.

AFFONSO, Rui B. A. Os municípios e os desafios da Federação no Brasil. São Paulo em Perspectiva, São Paulo, v. 10, n. 3, p. 3-10, 1996.

AZEVEDO, Paulo F. Nova economia institucional: referencial geral e aplicações para a agricultura. São Carlos: UFSCar, 2000. 
CALEGARI, Cesar. O Fundeb e o financiamento da educação pública no estado de São Paulo. 5. ed. atual. e ampl. São Paulo: Aquariana; Ibsa; Apeoesp, 2010.

CARVALHO, Sonia N. O sentido da mudança na legislação de uso do solo. São Paulo em Perspectiva, v. 9, n. 2, p. 52-56, 1995.

CARVALHO, Sonia N.; COSTA, Vicente. Políticas públicas, tomada de decisões e formação da agenda governamental. Cadernos Fundap, v. 8, n. 15, p. 103-110, 1988.

CASTRO, Jorge A. de. Financiamento da educação no Brasil. Em Aberto - Instituto Nacional de Estudos e Pesquisas Educacionais, v. 18, n. 74, p. 11-32, dez. 2001.

CASTRO, Jorge A. de; BARRETO, Angela R.; CORBUCCI, Paulo R. A reestruturação das políticas federais para o ensino fundamental: descentralização e novos mecanismos de gestão. Texto para Discussão no 745. Ipea, Rio de Janeiro, jul. 2000.

DAVIES, Nicolas. O Fundef e o orçamento da educação: desvendando a caixa preta. Campinas: Autores Associados, 1999.

FREY, Klaus. Políticas públicas: um debate conceitual e reflexões referentes à prática da análise de políticas públicas no Brasil. Planejamento e Políticas Públicas, Brasília, n. 21, p. 211-259, jun. 2000 .

LACZYNSKI, Patrícia. Fundef e seus impactos nos municípios: um estudo em dois municípios do estado de São Paulo. Dissertação (mestrado em administração pública e governo) — Escola de Administração de Empresas de São Paulo, Fundação Getulio Vargas, 2003.

LACZYNSKI, Patrícia. Políticas redistributivas e a redução das desigualdades: a contribuição potencial dos consórcios intermunicipais. Tese (doutorado em administração pública e governo) — Escola de Administração de Empresas de São Paulo, Fundação Getulio Vargas, 2012.

LOWI, Theodore. American business, public policy, case studies, and political theory. World Politics, v. 16, n. 4, p. 677-715, mar. 1964.

LOWI, Theodore. Decision making vs. policy making: toward an antidote fot technocracy. Public Administration Review, v. 30, n. 3, p. 314-325, 1970.

LOWI, Theodore. Distribuição, regulação, redistribuição [1966]. São Paulo, s.d.

LOWI, Theodore. Four systems of policy, politics, and choice. Public Administration Review, v. 32, n. 4, p. 298-310, 1972.

MILLER, Gary. Managerial dilemmas: the political economy of hierarchy. Canada: Cambridge University Press, 1992.

PERES, Ursula D. Arranjo institucional do financiamento do ensino fundamental no Brasil: considerações sobre os municípios brasileiros e estudo de caso do município de São Paulo no período de 1997 a 2006. Tese (doutorado) — Escola de Administração de Empresas de São Paulo, Fundação Getulio Vargas, 2007.

PINTO, José M. R. A política recente dos fundos para financiamento da educação e seus efeitos para o pacto federativo. Educ. Soc., v. 28, n. 100, p. 877-897, out. 2007. 
PINTO, José M. R. Os recursos para a educação no Brasil no contexto das finanças públicas. Brasília: Plano, 2000.

RAWLS, John. Uma teoria da justiça. Tradução de Almiro Pisetta e Lenita Esteves. São Paulo: Martins Fontes, 2000.

RICCI, Paolo. A medida das leis: do uso de noções genéricas à mensuração do imponderável. Revista Brasileira de Informação Bibliográfica em Ciências Sociais (BIB), São Paulo, n. 54, p. 101-122, 2002.

RODRIGUEZ, Vicente. Financiamento da educação e políticas públicas: o Fundef e a política de descentralização. Cadernos Cedes, Campinas, v. 21, n. 55, p. 42-57, 2001.

SANTOS, Maria H. C. Governabilidade, governança e democracia: criação de capacidade governativa e relações executivo-legislativo no Brasil pós-constituinte. Dados, Rio de Janeiro, v. 40, n. 3, p. 335-376, 1997.

SCHMITT, Maurílio Leopoldo. Regime fiscal brasileiro. Curitiba, 2009. Mimeografado.

Rogério Machado Limonti é bacharel em gestão de políticas públicas e pesquisador do Dieese. E-mail: rlimonti@dieese.org.br.

Ursula Dias Peres é doutora em economia e professora do Curso de Gestão de Políticas Públicas e dos Programas de Pós-graduação em Mudança Social e Participação Política e em Gestão de Políticas Públicas da EACH/USP. E-mail: uperes@usp.br.

Eduardo de Lima Caldas é doutor em ciência política e professor do Curso de Gestão de Políticas Públicas da EACH/USP.É bolsista de pós-doutorado da Capes no Cirad-França. E-mail: elcaldas@hotmail.com. 
